\title{
Serial Transverse Cross-Sectioning
}

National Cancer Institute

\section{Source}

National Cancer Institute. Serial Transverse Cross-Sectioning. NCI Thesaurus. Code C142148.

A histological method used to determine surgical marg in for skin tumors. The process involves cutting a specimen into 3 or more sections and examining a thin slice from each cut face. 